Principal maximum, February 20, I2h. 20m.; secondary maxima, February 20, I7h., February 22, 7h. $45 \mathrm{~m}$., and I6h. $30 \mathrm{~m}$. order of magnitude. Principal maximum, February 24, 7h. 50m.; secondary maximum, February 24, 22h. 5om. Principal maximum, February 25, 23h. 20m. ; secondary maximum, February 24, 9 h. $50 \mathrm{~m}$.

Epoch February 27, $23 \mathrm{~h}$, approximately sixth order of magnitude. Principal maximum, February 28, 6h.; secondary maximum, February 29, 9 h.

Epoch February 27, 14h. 3om., third order of magnitude. Principal maximum, February 29, 6h. 30m.; secondary maxima, February 27, 23h., and February 28, I2h. $40 \mathrm{~m}$.

There is a considerable number of meteor-showers in February, but the meteoric activity of the month is, in epochs in the foregoing list are the second and the last five.

JOHN R. HENRY.

The Question of Sun-spot Influence.

IN a paper to the Meteorologische Zeitschrift (September, I9II), Dr. Magelssen, dealing with sun-spot influence on temperature, finds this influence, at Christiania, \&c., most apparent in the winter half of the year. This is borne out, I think, by the data for Greenwich.

We might approach the matter thus: Taking the six maxima and six minima since $184 \mathrm{I}$, and confining atten-
Epoch February 26, 3h. 3om., approximately fourteenth

Epoch February 26, I4h., fourteenth order of magnitude. general, not so intense as in January. The most important

January 29

senting so much correspondence with each other and with the undulations of the sun-spot curve.

(The first point of the curve A I have marked as doubtful, for reasons $I$ need not here enter into.)

Alex. B. MacDowall.

\section{The Occurrence of Peripatus on the North-East} Frontier of India.

THE following extract from a letter just received from Mr. S. W. Kemp, zoologist with the Abor Expedition, will, I think, be of interest to the readers of NATURE, as it announces the first discovery of the Prototracheata in what may properly be called Continental Asia. The latter is dated Rotung, December 20, I9 I I :-

"Yesterday I toiled up to Kalek (3800 feet). .... On my return Hodgart, Mr. Kemp's assistant, rushed up with Peripatus in a tin, caught about 20 yards from me- one adult and two young. ... This morning we toiled for about four hours and got nine or ten more adults and a number of young. They occur over an area of about 30 square yards, and apparently nowhere else. The camp is made on an old Abor clearing. Prior to our occupation it was scrub jungle about 6 to 8 feet high, with a few large trees, mostly jack-fruit, interspersed. The scrub has been cut all round the camp, and on the north side, at the top of the steep bank dropping down to the Dihong River, Peripatus is found under large stones in comparatively dry earth.'

Mr. Kemp has as yet no opportunity of examining his specimens in a systematic manner; it will be of great interest from a geographical point of view to discover their genus in a restricted sense.

N. AnNANDALE.

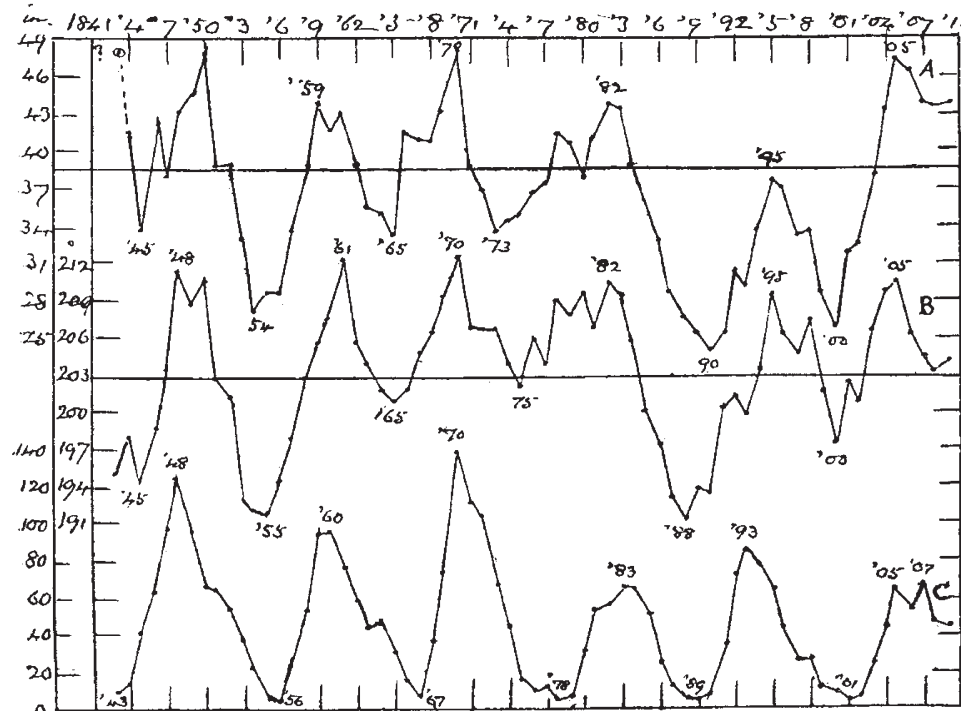

A. Rainfall, Rothesay, February-March ; smoothed, with sums of 5. B. Mean temp. Greenwich C. Sun-spot curve. Indian Museum, Calcutta, January II.

\section{Amphibian Faunas of South Africa} and Madagascar.

IN reference to the question raised by 38.6 the reviewer (NATURE, December I4, IgII) of my paper on the amphibian faunas of South Africa and Madagascar (Annals Transvaal Museum, April, 19r1), the distribution of the genus Rana suggests that it originated in the Old World some time subsequent to the isolation of Madagascar and the disruption of the $202: 9$ Brazil-West African land bridge, its passage to the New World being effected by a more northern bridge, probably the Bering Straits connection. The other Ranid genera of central and tropical America are unknown to me, but, judging from the descriptions, they form quite an isolated group, and if genetically related to the Old World Ranidæ had their origin, not in the specialised genus Rana, but in a more primitive Ranid stock which entered the New World by the Brazil-West African bridge.

John Hewitt.

Albany Museum, Grahamstown, South Africa, January 4 .

\section{A Bright Fireball}

tion to the groups " max. I, 2 " and "min. 1, 2," let us ask how many warm Januarys, Februarys, \&c., there were in those years (eighteen in either case). The most pronounced contrast (between maximum and minimum groups) thus comes out in the early part of the year, and (localising further) in the pair February-March.

If, now, we take the annual values of mean temperature for February-March, and smooth the series by simple addition of the groups $1841-5,1842-6$, and so on, (this is sufficient), we get the curve $B$ in the diagram.

Now, if we handle the monthly data of Rothesay rainfall in the same way, a maximum contrast comes out, similarly, in the early part of the year. Then, taking the annual amounts for February-March, and smoothing with sums of five, we have the curve A.

Below is the sun-spot curve, and it is remarkable, I think, to find things so far apart as Rothesay rainfall and Greenwich temperature in the February-March group preNO. 2205 , VOL. 88]
ON December I7, I9II, shortly after 5 p.m., while watching the dying glories of one of the loveliest sunsets I have ever seen, I saw a meteor fall in the west and burst into about twenty most brilliant balls, like an exploding rocket. I estimate that it appeared when about $20^{\circ}$ above the horizon, and traversed perhaps $5^{\circ}$ before bursting. It left a vertical and broad streak of white light on the sky, which very slowly became deffected from the perpendicular to the N.W., and when at about an angle of $45^{\circ}$ it faded gradually into two patches of white cloud, which uitimately assumed a horizontal position. These retained their pale white colour until after the other clouds had become quite dark, and they did not disappear until they were obscured by some of these clouds passing over them. It was seen from Beni-Hassan on the Nile, I67 miles south of Cairo, from the deck of one of Cook's steamers.

Aswan, Upper Egypt, January 19.
J. C. C. 